Janusz Mariański

John Paul II Catholic University of Lublin, Poland

\title{
Johannes Paul II. als moralische Autorität in der polnischen Gesellschaft
}

\section{Pope John Paul II as Moral Authority in Polish Society}

\section{Abstract}

The Author of the article assumes that the charisma of John Paul II - at least in the symbolic sphere - has impeded intensifying trends in Polish society toward moral permissivism and relativism in everyday life. In Polish society, the image of John Paul II remains not only as a moral authority and a model, but above all, he is seen as a person who throughout his whole life proved his worth as someone important to the core of Polish society. As an authority linked to the sacred sphere, he was, at the same time very human. Even among those who believe that in Polish society there are essentially no authorities left to look up to, one can find many people who are still inclined to recognize the Polish Pope as a significant moral authority. There is no doubt that John Paul II had a positive influence on the religiosity and general image of the Church in Poland, even though it is somehow difficult to measure that empirically. Experiences related to the Pope's illness, and later, to his death had a significant impact on many Poles from throughout society. One can question whether Polish Catholicism with its folk and mass nature will retain its prevailing character, now when Pope John Paul II is gone. Even if the impact of John Paul II on Polish moral and religious awareness will be decreasing, it still will be important and significant for some period of time. The strong impact of this exemplary Polish Pope is also going to slow down the secularization process of Polish society. All sociological data indicate that the influence of John Paul II on religiosity in his homeland will last for years to come, and hence, Poland will probably remain as a "specific case" in Europe with regards to the role religion plays in society. 


\section{Keywords}

John Paul II, moral authority, secularization, Polish society.

Der amerikanische Soziologe spanischer Herkunft José Casanova betont oft, dass der Katholizismus in Polen in der Zeit des Kommunismus keiner größeren Erosion unterlag und in den achtziger Jahren des vergangenen Jahrhunderts sogar eine gewisse Belebung und Erneuerung erfuhr. Im Zusammenhang mit den Prozessen der europäischen Integration verleiht ein Teil der Gläubigen und der kirchlichen Hierarchie ihrer Überzeugung Ausdruck, dass die polnischen Katholiken große apostolische Aufgaben gegenüber dem säkularisierten Europa zu erfüllen haben, während andere befürchten, dass Polen den Status eines katholischen Landes verliert und von radikalen Säkularisierungsströmungen mitgerissen wird. Casanova, der die „besondere Ausnahme“, die Polen im säkularisierten Europa darstellt, eher skeptisch betrachtet, schließt dennoch ein solches Szenarium der Entwicklung nicht aus, dass Polen seine katholische Identität bewahrt und der katholischen Tradition treu bleibt („Polonia semper fidelis"), auch unter den Bedingungen einer fortschreitenden europäischen Integration und sozialen Modernisierung. Das bedeutet, zumindest indirekt, dass zwischen Modernisierung und Säkularisierung kein deterministischer Zusammenhang besteht und dass die Säkularisierung Westeuropas keine historische Notwendigkeit war, sondern eine Wahlentscheidung der Europäer selbst. Ein modernes und religiöses Polen könnte Westeuropa „zwingen“, seine bisherigen Säkularisationsentscheidungen zu überdenken und zu begreifen, dass es tatsächlich bloß eine Ausnahme auf dem Welthintergrund darstellt ${ }^{1}$.

Die Meinungen über die katholische Kirche in Polen oder umfassender über den Katholizismus überhaupt sind recht differenziert. Einige Forscher sind der Ansicht, die katholische Kirche habe unter der Last ihrer Erfolge in den achtziger Jahren nach 1989 an Bedeutung verloren und würde ihre axiologische und integrative Kraft in der Gesellschaft auch weiterhin verlieren (die pessimistische Variante). Andere betonen die ständige Notwendigkeit einer Modernisierung des Katholizismus und sehen keinen Widerspruch zwischen Modernisierung und Religiosität in der polnischen Gesellschaft. Die starke Religiosität der Polen muss kein Hindernis für die soziale Modernisierung darstellen, sondern könnte

\footnotetext{
${ }^{1}$ Vgl. J. Casanova, Der Ort der Religion im nachchristlichen Europa, in: K. Michalski (Hrsg.), Woran glaubt Europa? Religion und politische Kultur im neuen Europa, Wien 2007, S. 38-40.
} 
diese sogar stärken (die optimistische Variante) ${ }^{2}$. Tadeusz Szawiel unterstreicht, dass die religiösen Praktiken in den Jahren 1992-2006 in Polen ein stabiles Niveau bewahrt haben, und zwar in allen Altersgruppen. Von den Jugendlichen im Alter von 18-24 Jahren besuchten 45-50\% mindestens einmal in der Woche die Kirche, von den älteren (über 29 Jahre) waren es 55\%. In diesem Bereich ist keine Richtungsänderung erkennbar ${ }^{3}$.

Seit zwanzig Jahren errichten wir eine neue Gesellschaft, eine Gesellschaft enormer Veränderung, Transformation und Modernisierung. Wir werden zu einer modernen und pluralistischen Gesellschaft und bewahren gleichzeitig - trotz gewisser negativer Trends - die Tradition und den christlichen Glauben. Familie, Nation und Kirche bilden zweifellos die Grundpfeiler der kulturbildenden und ethischen Rolle des polnischen Katholizismus. Und dann gibt es noch Johannes Paul II.! Wie wäre all das möglich ohne seine Unterweisung und sein Lebenszeugnis? Wie lange wird das Erbe Johannes Pauls II. seine gestaltende Kraft bewahren können für den polnischen Katholizismus, diesen „Ausnahmefall“ in Europa oder „das polnische Wunder“, wie andere sagen? Was wird aus dem polnischen Katholizismus nach dem Verlust seines allgemein verehrten Lehrers, Führers, Heiligen und Propheten? Ist die Rezeption seiner Unterweisung nicht etwa viel zu flach und oberflächlich?

Im Lichte von Befragungen der öffentlichen Meinung (Meinungsforschungsinstitute CBOS und TNS OBOP, Zentrum für Sozialumfragen OPINIA, Zentrum für das Denken von Johannes Paul II.) vertritt eine entschiedende Mehrheit der Polen die Ansicht, dass alle Pilgerfahrten des Papstes in seine Heimat eine wichtige Rolle für die sozialen und religiösen Wandlungen in der polnischen Gesellschaft gespielt haben, dass sie zu einem geistigen Quell der polnischen Transformationen wurden und auch im persönlichen Leben der Katholiken eine wichtige Rolle spielten. Die meisten unserer Landsleute sind davon überzeugt, dass die Unterweisung und das Lebenszeugnis Johannes Pauls II. im Leben der meisten Polen Wandlungen bewirkt haben, sowie dass auch sie selbst dem Papst eine Veränderung ihres eigenen Lebens verdanken. Etwas weniger Respondenten deklarieren, sie würden den Inhalt der päpstlichen Unterweisung kennen und sich in ihrem Leben auch von seinen Weisungen leiten lassen. Aus den deklarierten Meinungen über die geistige Verbundenheit mit dem Papst ergibt sich, dass wir seinem ideellen und moralischen Erbe treu sind.

${ }^{2}$ Vgl. Z. Nosowski, Modernizacja potrzebuje religii - i nawzajem, in: J. Szomburg (Hrsg.), Modernizacja Polski. Kody kulturowe i mity, Gdańsk 2008, S. 109-116.

${ }^{3}$ Vgl. T. Szawiel, Religijna Polska, religijna Europa, „Więź” 51 (2008) Nr 9, S. 32-33. 
Aber man kann die berechtigte Frage stellen, wie diese Überzeugungen und Meinungen im täglichen Verhalten ihren Ausdruck finden. Sind wir diesem Erbe auch in der Praxis treu? Oder haben diejenigen recht, die behaupten, dass der Papst bei uns allgemein geliebt, aber nicht gehört wird? Oder vielleicht ist es so, dass Johannes Paul II. „im Gedächtnis der Polen als eine nahestehende und zugleich anspruchsvolle Persönlichkeit fungiert: als Lehrer und religiöser Führer, der zeigt, wie man leben soll. Wenn man die zwei Jahre nach dem Ende seines Pontifikats geäußerten Meinungen der Polen analysiert, kann man den Eindruck gewinnen, dass Johannes Paul II. immer noch zu den Polen spricht und sie auch auf ihn hören, auch wenn die Stimme des Sprechenden allmählich schwächer wird.“ Und der Soziologe Krzysztof Koseła fügt hinzu: „Für die zeitgenössischen Polen war Johannes Paul II. sogar dann eine große Persönlichkeit, wenn er über Dinge sprach, denen sie nur schwer zustimmen konnten. Die außergewöhnliche Kraft der Person des Papstes bewirkte, dass sie ihn auch weiterhin gleichsam sehen und hören. Sie sind davon überzeugt, dass Johannes Paul II. sie verändert hat - und der Forscher könnte hinzufügen, dass er sie immer noch verändert" ${ }^{\star 4}$.

Der amerikanische Soziologe José Casanova unterstrich, dass Johannes Paul II. zu einem unermüdlichen Wanderer wurde, der als Fürsprecher der Menschheit und defensor hominis in der ganzen Welt die heilige Würde der menschlichen Person verkündete. „Dieser Papst lernte es, die Rolle des ersten Bürgers der gesamten katholischen (d.h. globalen und universellen) Gesellschaft der Menschen zu spielen. Man könnte geradezu sagen, dass der Papst zum Hohenpriester einer neuen, globalen, zivilgesellschaftlichen Religion der gesamten Menschheit wird"s. Die Wahl von Kardinal Karol Wojtyła zum Papst und die Rolle, die er in der Weltkirche und in unserem Land spielte, wurde und wird in der Welt unterschiedlich beurteilt. Die meisten Polen waren und sind von seiner Person fasziniert. Sogar diejenigen, die nicht institutionell mit der katholischen Kirche verbunden sind, äußerten sich positiv über ihn, sowohl über seine Persönlichkeit als auch über seinen Einfluss auf die Transformationsveränderungen in der polnischen Gesellschaft.

Eine außerordentlich wichtige Frage betrifft den Einfluss Johannes Pauls II. auf die polnische Religiosität. Manchmal wurde der Papst als Garant für die Vitalität des polnischen Katholizismus bezeichnet und die Überzeugung geäußert, er habe einen Schutzschirm über unser Land ausgebreitet, seelsorgliche Visionen geliefert und konkrete Anleitungen zum Handeln gegeben. Zweifellos hat die

${ }^{4}$ Vgl. K. Koseła, Opinie o pontyfikacie Jana Pawła II, in: T. Żukowski (Hrsg.), Wartości Polaków a dziedzictwo Jana Pawła II, Warszawa 2009, S. 123, 149.

${ }^{5}$ J. Casanova, Katolicyzm a sekularyzacja, „Znak” (2008) Nr 10, S. 83. 
Person Johannes Pauls II. einen positiven Einfluss auf das Bild der Religiosität und der Kirche in Polen, auch wenn diese empirisch wohl nicht messbar ist. Vom soziologischen Gesichtspunkt aus sind wir nicht imstande, so etwas wie ein kontrolliertes Experiment durchzuführen, um festzustellen, wie die moralische Kondition der polnischen Gesellschaft ausgesehen hätte, wenn unser Landsmann nicht den Stuhl Petri bestiegen hätte. Welche Konsequenzen für die ethische Rolle des Katholizismus in Polen hat das Pontifikat Johannes Pauls II. für die Hemmung der Prozesse der Laizisierung (Säkularisierung)? Was verdanken wir ihm beim Übergang vom realsozialistischen System zur Demokratie? Wie beurteilen die Polen Johannes Paul II. am Ende der ersten Dekade des 21. Jahrhunderts? Ist er auch weiterhin eine moralische Autorität für sie, und in welchem Umfang?

Schon heute zeichnet sich in Kreisen der Jugend eine gewisse Polarisierung der Einstellungen und Verhaltensweisen in religiösen Dingen ab. Einerseits nehmen die Kreise engagierter und religiös aktiver Jugendlicher zu, andererseits wächst aber auch die Zahl derer, die den institutionellen Dimensionen des Katholizismus gleichgültig oder kritisch gegenüberstehen. Die Generation „JP2“ ist ein Hoffnungsträger der polnischen Kirche, selbst wenn das mit dem Tod des Papstes verbundene Trauma nur vorübergehenden Charakter hatte ${ }^{6}$. Von sich aus allein entsteht dadurch noch keine besondere und spezifische Generation junger Polen. Dies steht nicht im Widerspruch zu der These, dass die Verbundenheit der Polen mit Johannes Paul II. einen spezifischen Charakterzug der polnischen Religiosität bildet. Diese Verbindung zwischen der polnischen Religiosität und der Person Johannes Pauls II. beschreiben Mirosława Marody und Sławomir Mandes wie folgt: „In der Zeit des 25-jährigen Pontifikats Johannes Pauls II. hat sich im Leben der Polen praktisch alles verändert: das politische und das ökonomische System, die politischen Parteien, die propagierten Werte und die Handelsstrategien. Der Papst schien das einzige stabile Element in ihrer kollektiven Identität zu sein. In allen Befragungen über die wichtigsten Persönlichkeiten der polnischen Geschichte nahm er den höchsten Platz ein. Selbst die geringste Kritik an seiner Person stieß auf allgemeine Verurteilung, und selbst vorsichtig formulierte Fragen nach den Veränderungen, die nach seinem Tod in der katholischen Kirche zu erwarten seien, stießen auf Konsternation. Der Papst wurde zur Ikone und zum Garanten der Identität der Polen, und solange er lebte, konnte sich diese Identität nur durch religiöse Rituale manifestieren. Deshalb war der Tod Johannes Pauls II.

${ }^{6}$ T. Szawiel (Hrsg.), Pokolenie JP2. Przeszłość i przyszłość zjawiska religijnego, Warszawa 2008. 
für die Polen ein Augenblick der mächtigsten Manifestation nationaler Einheit seit der Zeit der ersten Solidarnośćc"?.

\section{Die Autorität Johannes Pauls II. im Lichte von Befragungen öffentlicher Meinungsforschungsinstitute}

Der polnische Soziologe Edmund Wnuk-Lipiński spricht von geistiger Führerschaft, die ,eine Gruppe von Personen [bildet], welche Standards der Rechtschaffenheit oder Schicklichkeit im kollektiven Leben formuliert, die von einem so bedeutsamen Teil der Gesellschaft ohne Zwang, ja sogar gern akzeptiert werden, dass diese Standards zu sozialen Normen werden, welche die Haltungen und Verhaltensweisen Einzelner sowie ganzer sozialer Gruppen beeinflussen. Die einzige Strafandrohung bei Übertretung dieser Normen ist die Herabsenkung der Selbsteinschätzung auf der Skala der Anständigkeit. Dies jedoch ist eine sehr schmerzliche Strafe, wenn Normen verletzt werden, die als die eigenen anerkannt werden " ${ }^{\text {" }}$. Während in den achtziger Jahren des vergangenen Jahrhunderts in Polen (nicht nur bei den geistigen Eliten) eher ein Denken in Kategorien von recht und billig als von nützlich dominierte, veränderte sich die Situation in den neunziger Jahren. „Das Denken in Kategorien von recht und billig macht einem Denken in Kategorien des politischen Interesses Platz, d.h. dessen, was zur Erringung und Wahrung der Macht nützlich ist. Der Mythos der Gleichheit verfällt. Die horizontalen Bindungen unterliegen einer allmählichen Atrophie, und an ihrer Stelle treten neue vertikale Bindungen in Erscheinung und werden petrifiziert. Geistige Führerschaft verwandelt sich allmählich in politische Führerschaft, welche sich von einer völlig anderen Logik leiten lässt. Die Effektivität beim Erreichen von Zielen wird wichtiger als die Treue gegenüber den anerkannten Normen der Anständigkeit. Dieser spezifisch polnische - oder vielleicht umfassender: mitteleuropäische - Prozess wird überlagert von einer globalen Tendenz, die wie eine aufgestaute Welle über Polen hereinbrach, als die vom Kommunismus errichteten Schranken fielen - von einer postmodernistischen Tendenz, die die traditionellen Hierarchien und gefestigten Bereiche kollektiver Sinngebung stark in Frage stellt ${ }^{\star 69}$.

${ }^{7}$ M. Marody, S. Mandes, Polak katolik. O zwiqzkach religijności z tożsamościq narodowa, „Dziennik” (dodatek „Europa” Nr 24) (2006) Nr 48, S. 9.

${ }^{8}$ E. Wnuk-Lipiński [głos w dyskusji], in: S. Bednarek, A. J. Omelaniuk, A. Tyszka, A. Zieliński (Hrsg.), Kongres Kultury Polskiej 2000, Wrocław-Warszawa 2002, S. 77-78.

${ }^{9}$ Ibidem, S. 79. 
Sowohl in der Gesellschaft als auch in der katholischen Kirche ist von einer Krise derAutorität, des Vertrauens und der Legitimation die Rede. DieEntfremdung breiter Schichten der Bevölkerung vom Einfluss institutioneller Autoritäten verstärkt sich, besonders solcher, die allgemeine Gültigkeit beanspruchende Normen verkünden. Durch die Desinstitutionalisierung, Pluralisierung und Individualisierung der moralischen Werte werden alle institutionellen Autoritäten geschwächt. In der polnischen Gesellschaft der neunziger Jahre des vergangenen Jahrhunderts und im darauffolgenden Zeitraum kam es zu einer vehementen Änderung der öffentlichen Autoritäten, sowohl der persönlichen als auch der institutionellen, sowohl der politischen als auch der moralischen. Viele traditionelle Autoritäten werden in Frage gestellt oder abgelehnt, aber nur in viel geringerem Maße wird nach neuen gesucht. Im Ergebnis der Untersuchungen des Meinungsforschungsinstituts CBOS vom September 2009 akzeptierten 74,0\% der befragten erwachsenen Polen die These, es sei wichtig, im Leben persönliche Vorbilder zu haben, denen nachzueifern lohnt, aber nur 48,5\% der Befragten gaben an, dass es in ihrem Leben eine solche Person gibt oder gab, die einen besonderen Einfluss auf sie ausübte und von der sie sagen könnten, sie sei eine Autorität oder ein Vorbild für sie. Noch seltener wurden solche Personen im öffentlichen Leben wahrgenommen $(34,5 \%)^{10}$.

In einer Zeit der Autoritätskrise in der polnischen Gesellschaft nahm die Person Johannes Pauls II. einen besonderen Platz ein. Die große religiöse und moralische Autorität Johannes Pauls II. in der polnischen Gesellschaft bestätigen die Ergebnisse der Meinungsumfragen, und zwar sowohl die aus den achtziger als auch aus den neunziger Jahren und die vom Beginn des 21. Jahrhunderts. Einige Ergebnisse dieser Befragungen sollen im folgenden angeführt werden. Der CBOS-Untersuchung vom August 2002 zufolge bezeichneten sich 17\% der erwachsenen Polen ganz entschieden als Menschen, die sich im täglichen Leben, in ihren Ansichten, ihrem Verhältnis zu den Mitmenschen, zur Arbeit und in anderen Dingen von den Weisungen und Lehren Johannes Pauls II. leiten lassen, $60 \%$ - eher ja, $11 \%$ - eher nein, 3\% - unentschieden und 9\% - schwer zu sagen. Diese Deklarationen hinsichtlich der Einhaltung der Glaubensprinzipien und der vom Papst verkündeten Normen sind in beträchtlichem Grade von der Teilnahme an den religiösen Praktiken abhängig (mehrmals wöchentlich praktizierend $97 \%$, einmal wöchentlich $-85 \%$, ein- oder zweimal im Monat $-76 \%$, einige Male im Jahr - 64\%). Selbst bei den überhaupt nicht praktizierenden Personen

${ }^{10}$ Vgl. Aktualne problemy $i$ wydarzenia (232). Komunikat $\mathrm{z}$ badań CBOS (do użytku wewnętrznego), Warszawa 2009, S. 28. 
meinen mehr als die Hälfte, sie würden sich in ihrem täglichen Leben bemühen, der päpstlichen Unterweisung zu folgen ${ }^{11}$.

Den Ergebnissen einer CBOS-Untersuchung vom Oktober 2003 zufolge hielten sich $65 \%$ der befragten erwachsenen Polen für Menschen, die die päpstliche Unterweisung kennen (15\% - entschieden ja, 50\% - eher ja), 31\% gaben zu, die päpstliche Unterweisung nicht zu kennen, und $4 \%$ waren unentschieden in der Frage nach der Beurteilung ihres diesbezüglichen Wissens. Die Mehrheit der Befragten war der Ansicht, die Erwartungen des Papstes an die Polen seien für sie nicht schwierig zu erfüllen (19\% - entschieden nicht zu schwierig, $48 \%$ - eher nicht zu schwierig). Aber fast ein Viertel der Befragten gab zu, dass es ihnen schwerfällt, den Erwartungen des Papstes gerecht zu werden (23\%), und jeder zehnte Respondent hatte in dieser Angelegenheit keine eigene Meinung (10\%). Insgesamt waren die befragten Polen der Meinung, dass gläubige Menschen die geringsten Schwierigkeiten hätten, die Erwartungen des Papstes zu erfüllen (diese Ansicht äußerten 21\% aller Befragten), während die Jugend (36\%) und die Gesellschaft als Ganzes (37\%) damit schon öfter Schwierigkeiten hätten und am meisten die gegenwärtig an der Macht befindlichen Politiker (52\%). Die entschiedene Mehrheit der Respondenten stimmte der Ansicht zu, dass die Polen den Papst zwar lieben würden, jedoch im Alltag seine Ratschläge, Empfehlungen und Aufrufe im allgemeinen nicht befolgten. Nur $11 \%$ der Befragten widersprachen einer solchen Einschätzung der Polen in Bezug auf den Papst und seine Unterweisung (4\% wählten die Antwort: „schwer zu sagen“). Diese kritische Einschätzung der Gesellschaft korrespondiert somit nicht mit der Meinung der Befragten von sich selbst $\mathrm{t}^{12}$.

In der Befragung vom Juli 2005 ging es u.a. um den Einfluss verschiedener Personen und Institutionen auf die Ansichten der erwachsenen Polen über die Welt und das Leben überhaupt. An erster Stelle wurden eigene Überlegungen genannt ( $81 \%$ bezeichneten diesen Einfluss als stark), an zweiter Stelle der Papst Johannes Paul II. (80\%), danach die Eltern (77\%), die religiösen Prinzipien, der Glaube (64\%), die Lehrer (43\%), die Großeltern (34\%), Priester und Katecheten (31\%), Literatur, Schriftsteller (27\%), Kollegen und Freunde (26\%), die Medien, d.h. Presse, Rundfunk, Fernsehen und Internet (20\%) sowie herausragende historische Persönlichkeiten (19\%). Die übrigen Respondenten beriefen sich bei

${ }^{11}$ Vgl. B. Roguska, B. Wciórka, Religijność i stosunek do Kościoła katolickiego, in: K. Zagórski, M. Strzeszewski (Hrsg.), Polska. Europa. Świat. Opinia publiczna w okresie integracji, Warszawa 2005, S. 324-325.

${ }^{12}$ Vgl. B. Wciórka, Czy Polacy spetniaja oczekiwania Papieża. Komunikat z badań CBOS. BS/158/2003, Warszawa 2003, S. 11-17. 
der Bestimmung des Einflusses dieser Faktoren auf die Antworten: ,gering“, ,gar keiner“ oder „schwer zu sagen“"13.

Der CBOS-Befragung vom April 2006 zufolge bezeichneten sich 15\% der befragten erwachsenen Polen als Menschen, die den Inhalt der Unterweisung des Papstes sehr gut kennen, 57\% - eher ja (zusammen kennen sie also 72\%), $21 \%$ - eher nein, $3 \%$ - überhaupt nicht und $4 \%$ - schwer zu sagen. Über drei Viertel der Befragten waren der Ansicht, sie würden sich in ihrem Leben von den Weisungen des Papstes leiten lassen (18\% - entschieden ja, 60\% - eher ja), und nur jeder Fünfte widersprach dem (eher nein $-15 \%$, entschieden nein - 3\%), schwer zu sagen $-4 \%)^{14}$. „Es steht außer Zweifel, dass die Person Johannes Pauls II. für die Religiosität der Polen sowie ihre Verbundenheit mit der Kirche sehr wesentlich war. Die Verbundenheit mit seinem Nachfolger, wie sie in der Kenntnis der Unterweisung des jetzigen Papstes und der Befolgung seiner Weisungen zum Ausdruck kommt, ist nicht mehr so stark. Zwei Jahre nach dem Tode des polnischen Papstes können gewisse Symptome einer Schwächung der Verbindung mit der Kirche beobachtet werden, die unter anderem in einer etwas geringeren Aufmerksamkeit für ihre Unterweisung zum Ausdruck kommen. Aber selbst wenn eine Schwächung der Verbundenheit mit der institutionellen Kirche eingetreten ist, so äußert sich diese dennoch nicht in der Frequenz der Teilnahme der Polen an den religiösen Praktiken, welche sich seit Jahren auf annähernd gleichem Niveau hält"“15.

Im Mai 2009 waren - wie aus der CBOS-Befragung hervorgeht - für 68,7\% der erwachsenen Polen alle Pilgerreisen Johannes Pauls II. in sein Vaterland für die Respondenten gleich wichtig, für 21,9\% waren einige Pilgerreisen besonders wichtig, für $6,5 \%$ der Respondenten hatte keine von ihnen besondere Bedeutung (2,9\% - keine Meinung oder Antwort verweigert). Noch größere Bedeutung maßen die Befragten den Pilgereisen des Papstes in ihrer Bedeutung für Polen zu (entsprechend 71,1\%; 23,8\%; 2,0\%; 3,1\%). Die Hälfte der Befragten hielt die Pilgerreise von 1979 für besonders wichtig, was ihre persönliche Bedeutung für den Respondenten anbelangt (50,4\% aller Befragten), und über drei Viertel hielten sie für wichtig für das Land (80,6\%). Nach Meinung von $69,5 \%$ aller Befragten trugen das Lebenszeugnis und die Unterweisung Johannes Pauls II. zur Veränderung des Lebens der Respondenten bei, nach Meinung von 81,1\% - der

\footnotetext{
${ }^{13}$ R. Boguszewski, Wartości i normy w życiu Polaków. Komunikat z badań CBOS. BS/133/2005, Warszawa 2005, S. 4.

${ }^{14}$ Vgl. R. Boguszewski, Polacy wobec Kościoła oraz nauczania papieża Benedykta XVI dwa lata po śmierci Jana Pawła II. Komunikat z badań CBOS. BS/78/2007, Warszawa 2007, S. 3-4.

${ }^{15}$ Ibidem, S. 5.
} 
meisten Polen; 70,7\% der Befragten deklarierten, den Inhalt der Unterweisung Johannes Pauls II. zu kennen; 72,6\% ließen sich in ihrem Leben von den Weisungen des Papstes leiten; aber nur 42,6\% sprachen sehr oft oder oft über Johannes Paul II.; 33,0\% beteten sehr oft oder oft für seine Seligsprechung und 21,4\% baten Johannes Paul II. im Gebet um Hilfe in einer konkreten Angelegenheit ${ }^{16}$.

Die überwiegende Mehrheit der 2009 befragten Polen war sich bewusst, dass die erste Pilgerreise Johannes Pauls II. nach Polen zur Entstehung der „Solidarnośćc"-Bewegung im August 1980 (78\% der Befragten) sowie zum Sturz des Kommunismus und zur Wiedererlangung der Unabhängigkeit Polens im Jahre 1989 (78\%) beigetragen hat. Die entschiedene Mehrheit der Polen ist davon überzeugt, dass die Pilgerreisen Johannes Pauls II. in sein Heimatland eine wichtige Rolle in der Geschichte Polens und in ihrem persönlichen Leben gespielt haben. „Die Polen sind auch übereinstimmend der Ansicht, dass das Lebenszeugnis und die Unterweisung Johannes Pauls II. das Leben der meisten ihrer Landsleute verändert haben. Vor allem ist die überwiegende Mehrheit der Meinung, sie selbst würden Johannes Paul II. eine Veränderung ihres Lebens verdanken. Es muss hervorgehoben werden, dass die heute Befragten von einem solchen Einfluss des Papstes stärker überzeugt sind als ein Jahr nach seinem Tod. Die meisten deklarieren auch, den Inhalt der päpstlichen Unterweisung zu kennen (auch in dieser Hinsicht hat sich in den letzten Jahren nichts geändert). Damit geht die - von den meisten Respondenten geäußerte - Überzeugung einher, dass sie sich in ihrem Leben von den Weisungen Johannes Pauls II. leiten lassen. Aber die päpstliche Unterweisung fungiert heute für eine kleinere Gruppe von Befragten als Wegweiser, als dies noch vor drei und besonders vor vier Jahren der Fall war. Außerdem zeigte es sich, dass die meisten der Befragten im Verlauf des letzten Jahres die Erinnerung an den Papst als ihren Landsmann bewahrt haben. Ähnlich wie vor drei Jahren erinnerten sich fast alle an ihn, die überwiegende Mehrheit betete für seine Seligsprechung, und über die Hälfte wandte sich in für sie wichtigen Angelegenheiten im Gebet mit Bitten an ihn. Allerdings taten die Untersuchungspersonen dies alles mit einem etwas geringeren Engagement als noch ein Jahr nach dem Tode des Papstes“17.

Die geistige Verbundenheit der Katholiken in Polen mit Johannes Paul II. ist immer noch stark, und sie sind - ihrer Deklaration zufolge - auch weiterhin dem Erbe treu, das er ihnen hinterlassen hat. Ein charakteristisches Merkmal der

${ }^{16}$ Vgl. Aktualne problemy $i$ wydarzenia (228). Komunikat $\mathrm{z}$ badań CBOS (do użytku wewnętrznego), Warszawa 2009, S. 19-22.

${ }_{17}$ B. Wciórka, Pierwsza pielgrzymka Jana Pawła II do ojczyzny - rocznicowe refleksje. Komunikat z badań CBOS. BS/83/2009, Warszawa 2009, S. 22. 
polnischen Religiosität bildete - wie aus den öffentlichen Meinungsumfragen hervorgeht - die Verbundenheit der Polen mit Johannes Paul II. Sein Nachfolger Benedikt XVI. erfreut sich zwar ebenfalls großer Autorität, die aber etwas geringer ist als die seines Vorgängers. Dem Meinungsforschungsinstitut CBOS zufolge deklarierten im April 2007 45\% der befragten Polen, den Inhalt der päpstlichen Unterweisung zu kennen (9\% - entschieden ja und 36\% - eher ja), während sich die Hälfte der Befragten diesbezüglich zur Unkenntnis bekannte (eher nein $-36 \%$, entschieden nein $-12 \%$, schwer zu sagen $-7 \%$ ). Etwa die Hälfte der untersuchten erwachsenen Polen hielt sich für Menschen, die sich in ihrem Leben von den Weisungen Benedikts XVI. leiten lassen (entschieden ja $11 \%$, eher ja - 38\%), während etwas mehr als jeder dritte Befragte dies verneinte ( $28 \%$ - eher nein, $10 \%$ - entschieden nein, 13\% - schwer zu sagen). Die Kenntnis der Unterweisung Benedikts XVI. sowie die Befolgung seiner Weisungen ist im höchsten Maße hinsichtlich des Niveaus der realisierten religiösen Praktiken differenziert, in allgemeinen Dimensionen jedoch deutlich schwächer als in Bezug auf Johannes Paul $\mathrm{II}^{18}$.

Das Verhältnis der Polen zu ihrem Papst Johannes Paul II. bildete den Gegenstand zahlreicher vom Meinungsforschungsinstitut OBOP durchgeführter Befragungen. Im Ergebnis der im November 2006 von OBOP auf der Basis eines im Zentrum für das Denken Johannes Pauls II. erstellten Fragebogens durchgeführten Untersuchung „Die Polen und ihre Gesellschaft in der Zeit Johannes Pauls II.“ wurde festgestellt, dass fast drei Viertel aller Polen für eine Seligsprechung Johannes Pauls II. beteten (55\% - ja, viele Male; $18 \%$ - ja, mindestens einmal), während jeder vierte Pole überhaupt nicht betete $(25 \%$; $2 \%$ - schwer zu sagen). Frauen (82\%) beteten öfter als die Männer (62\%) für eine Seligsprechung, Personen mit Grundschulbildung (82\%) öfter als solche mit höherer Bildung (54\%), auf dem Lande lebende Personen (83\%) öfter als Großstadtbewohner (56\%). Ihre Gebete erwähnten die jüngsten Personen $(76 \%)$ genauso oft wie die ältesten (78\%). Für eine Seligsprechung beteten die praktizierenden Katholiken, aber auch jeder Fünfte von denen, die nicht zum Gottesdienst in die Kirche kommen. In der gesamten Probe deklarierten 73\% der befragten Polen ausdrücklich, dass Johannes Paul II. für sie eine wichtige moralische Autorität darstellte, 21\% - eher ja (zusammen 94\%), 3\% - eher nein, $2 \%$ - entschieden nein und 1\% - schwer zu sagen). Gleichzeitig erklärten $94 \%$ der Befragten, dass Johannes Paul II. „ihr“ Papst sei. Nicht anerkannt wurde die moralische Autorität des Papstes von nur 2\% der Anhänger rechtsgerichteter

${ }^{18}$ Vgl. R. Boguszewski, Polacy wobec Kościoła oraz nauczania papieża Benedykta XVI dwa lata po śmierci Jana Pawta II. Komunikat z badań CBOS. BS/78/2007, Warszawa 2007, S. 3-4. 
und von 12\% der Anhänger linker Parteien, von 3\% der Arbeiter, von 19\% der Spezialisten und Führungskräfte sowie von $30 \%$ der überhaupt keine Kirche besuchenden Personen ${ }^{19}$.

Bei der Beurteilung der Person Johannes Pauls II. war für die Mehrheit der Polen die universelle Dimension seiner Botschaft wichtig. In der gesamten Probe der untersuchten erwachsenen Polen fungierte Johannes Paul II. vor allem als ein Führer für die ganze Welt (bei 59\% der Befragten), dann als moralische Autorität (58\%), als Führer unserer Nation (29\%), als religiöser Führer (29\%), als Nachfolger des hl. Petrus (27\%), als Lehrer (19\%), als Anführer unserer Gesellschaft (12\%), als eine Art Vaterfigur (11\%), oder aber als ,niemand Besonderes, mir gleichgültig“ (1\%). Die Anerkennung des Papstes als moralische Autorität war deutlich vom Bildungsgrad abhängig. Als besonders wichtig angesehen wurde diese Rolle Johannes Pauls II. von über zwei Dritteln der Befragten mit höherer Bildung (69\%), von fast drei Fünfteln mit mittlerer oder Fachschulbildung und von weniger als der Hälfte mit Grundschulbildung (44\%). Was das Alter der Befragten betrifft, so erwähnten die Personen im Alter zwischen 30 und 39 Jahren die moralische Autorität des Papstes am seltensten $(47 \%)^{20}$.

Die religiöse und moralische Botschaft des Papstes erreichte sehr viele Menschen. In der Gesamtprobe nahmen 47\% der Befragten während seiner Pilgerreisen in sein Heimatland mindestens einmal an einer Heiligen Messe teil, $50 \%$ lasen den Inhalt seiner Predigten in der Presse, 30\% lasen eines der von Johannes Paul II. verfassten Bücher, und 92\% verfolgten seine Predigten im Rundfunk oder im Fernsehen. In der Konsequenz dieser Deklarationen waren die meisten der Befragten davon überzeugt, die Unterweisung Johannes Pauls II. zu kennen (16\% - entschieden ja und 57\% - eher ja). Die überwiegende Mehrheit der befragten Polen hielt sich „entschieden ja“ oder „eher ja“ für Menschen, die sich in ihrem Leben von den Weisungen Johannes Pauls II. leiten lassen (81\%), deren persönliches Leben sich verändert hat (64\%), und etwa 70\% gaben an, das Lebenszeugnis und die Unterweisung des Papstes habe in einem gewissen Grade zur Veränderung des Lebens der meisten Polen beigetragen. In den Tagen der Krankheit, des Todes und der Beisetzung Johannes Pauls II. begleiteten die Polen folgende Gefühle: Vereinsamung - 67\% aller Befragten, Gemeinschaftsgefühl $84 \%$, Befürchtungen $-67 \%$, Hoffnung $-57 \%$. $71 \%$ der Befragten deklarierten,

${ }^{19}$ Vgl. Centrum Myśli Jana Pawła II. Jan Paweł II w opinii Polaków. Raport z badań społecznych Centrum Myśli Jana Pawła II w Warszawie, Warszawa 2007, S. 5-8.

${ }^{20}$ Ibidem, S. 13-14. 
sie würden sich der „Generation JP2“ zugehörig fühlen (43\% - entschieden ja und $28 \%$ - eher ja $)^{21}$.

In den vom Meinungsforschungsinstitut CBOS im Auftrag des Zentrums für das Denken Johannes Pauls II. im Herbst 2007 durchgeführten Untersuchungen verfolgten $91 \%$ der befragten Polen mindestens einmal eine Predigt Johannes Pauls II. im Rundfunk oder im Fernsehen bzw. in der Presse; 71\% erklärten, sie hätten im Kreis der Familie oder bei Freunden und Bekannten vom Papst erzählen hören; 46\% nahmen an Heiligen Messen während der Pilgerreisen des Papstes in seine Heimat teil; 38\% hatten ein vom Papst verfasstes Buch gelesen; $60 \%$ beteten zu Johannes Paul II. um seine Fürsprache bei Gott in einer wichtigen Angelegenheit; 61\% erzählten ihren Familienmitgliedern oder Bekannten vom Papst; 63\% beteten für die Seligsprechung des Papstes; 29\% bemerkten in ihrem eigenen oder im Leben ihrer Nächsten Veränderungen, die mit dem Einfluss Johannes Pauls II. im Zusammenhang stehen; 79\% hielten sich für Menschen, die sich in ihrem Leben von den Weisungen des Papstes leiten lassen; 63\% meinten, das Lebenszeugnis und die Unterweisung Johannes Pauls II. habe in gewissem Grade zur Veränderung ihres Lebens beigetragen; 94\% erkannten die moralische Autorität des Papstes an (,entschieden ja“ oder „eher ja“); 63\% der Befragten beurteilten entschieden positiv, was Johannes Paul II. während seines Pontifikats für die Welt von heute getan hat, $33 \%$ - eher positiv 22 .

Die 2007 befragten Polen beurteilten auch die Sorge ihrer Landsleute um das von Johannes Paul II. hinterlassene Erbe, d.h. sie beurteilten die moralische Kondition der polnischen Gesellschaft, wie die Polen die päpstlichen Weisungen für ein Leben im Einklang mit den moralischen Prinzipien verwirklichen. Insgesamt stellten 31\% aller Befragten fest, die Polen würden das Erbe der „Solidarnośćc“ pflegen; $43 \%$ - dass sie sich freundlich und respektvoll zueinander verhalten; 49\% - dass sie ihre Freiheit richtig nutzen; 51\% - dass sie Armen, Leidenden und Hilfsbedürftigen helfen; 53\% - dass sie das Leben der ungeborenen Kinder schützen; 53\% - dass sie die Liebe zu ihrem Vaterland, den Patriotismus und die historische Erinnerung pflegen; 57\% - dass sie sich bemühen, ehrlich und ihrem Gewissen gemäß zu leben; 62\% - dass sie der Kirche treu sind; 63\% - dass sie ihren Glauben stärken und oft beten; $65 \%$ - dass sie für die religiöse Erziehung der Kinder und Jugendlichen Sorge tragen; 66\% - dass sie die familiären Werte und ihr Familienleben pflegen ${ }^{23}$.

${ }^{21}$ Vgl. Ibidem, S. 15-26.

${ }^{22}$ Vgl. K. Koseła, Opinie o pontyfikacie Jana Pawła II, in: T. Żukowski (Hrsg.), Wartości Polaków a dziedzictwo Jana Pawła II, Warszawa 2009, S. 124-132.

${ }^{23}$ Vgl. Ibidem, S. 140. 
Was die Wahrung der vom Heiligen Vater als wichtig aufgewiesenen Werte betrifft, fällt das Urteil über die Bemühungen der polnischen Gesellschaft ziemlich positiv aus. „Die meisten skeptischen Antworten treten nur im Falle von Fragen in Erscheinung, ob die Polen ihre Freiheit richtig nutzen, ob sie sich zueinander freundlich und respektvoll verhalten und ob sie das Erbe der „Solidarnośćc pflegen. Im Schatten der Erinnerungen an die Person Johannes Pauls II. verringert sich sogar die Misanthropie der Polen. Die Diagnose der Kondition der polnischen Gesellschaft nach dem Abschluss des Pontifikats Johannes Pauls II. fällt also ganz positiv aus. Aber man darf nicht vergessen, dass sie nicht nur für die Respondenten schwierig zu formulieren war, sondern auch den Forschern Interpretationsschwierigkeiten bereitet. Die Feststellung, dass die heutigen Polen ihre Freiheit verantwortlich nutzen, kann sich auf ihr Verhalten im öffentlichen Bereich beziehen, d.h. in Bezug auf den Staat und die Nation. Sie kann auch bedeuten, dass sich die Polen heute um die Wahrung der sittlichen Ordnung auf dem Gebiet der zwischenmenschlichen Beziehungen, in den Gemeinschaften und Vereinen kümmern" ${ }^{\text {"24 }}$.

Sehr interessante Ergebnisse lieferten die Antworten auf die Fragen nach der Akzeptanz bzw. Ablehnung bestimmter Bestandteile der Lehre Johannes Pauls II. Die Kennziffern völliger Akzeptanz präsentierten sich wie folgt: hinsichtlich seiner Bestrebungen zur Ökumene (Verständigung aller christlichen Konfessionen) - 66\%; zur Verständigung des Christentums mit dem Judentum 55\%; zur Verständigung des Christentums mit dem Islam - 50\%; sein Einspruch gegen die rechtliche Gleichstellung homosexueller Lebensgemeinschaften mit der Ehe - 61\%; seine Ablehnung der Priesterweihe für Frauen - 47\%; sein Widerspruch gegen die Euthanasie (Kürzung des Lebens schwer kranker bzw. alter Personen) - 36\%; gegen den Schwangerschaftsabbruch - 26\%; seine Verurteilung der Todesstrafe $-34 \%$; seine Missbilligung der Verwendung von Empfängnisverhütungsmitteln - 15\%. „Auf die unbedingte Akzeptanz der meisten Respondenten stieß der päpstliche Einspruch gegen die rechtliche Gleichstellung homosexueller Lebensgemeinschaften mit der Ehe, während die vatikanische Ablehnung der Priesterweihe für Frauen mehrheitlich nicht bedingungslos akzeptiert wurde. Zweifel bei einer größeren Gruppe von Respondenten weckt der Standpunkt des Papstes in Bezug auf die Euthanasie. Noch weniger generell akzeptiert wird der päpstliche Standpunkt in Sachen Abtreibung und Todesstrafe. Die Überzeugung, dass das Leben des Menschen unter gar keinen Umständen beendet werden darf, stieß bei den Polen nicht auf die allgemeine Anerkennung.

\footnotetext{
${ }^{24} \mathrm{Vgl}$. Ibidem, S. 140.
} 
Am wenigsten akzeptiert wird die Stimme Johannes Pauls II. im Streit um die Schwangerschaftsverhütung “25.

In Polen genoss Johannes Paul II. das größte Vertrauen, viel mehr als die übrigen Institutionen des sozialen Lebens. Gemäß den Untersuchungen des Meinungsforschungsinstituts OPINIA aus dem Jahre 2002 brachten 87,0\% aller befragten Polen dem Papst ihr völliges Vertrauen entgegen, 9,3\% - nur ein eingeschränktes Vertrauen, 1,3\% gar kein Vertrauen; 2,4\% - schwer zu sagen oder keine Antwort. Die Haltung des eingeschränkten Vertrauens wurde verhältnismäßig öfter von dem Glauben gegenüber gleichgültigen oder unentschlossenen, nicht praktizierenden Personen, von Arbeitslosen, Kaufleuten, Geschäftsleuten und Unternehmern, von Personen im Alter von 18 bis 34 Jahren, Schülern oder Studenten, Personen mit Mittel- oder Hochschulbildung und von Männern deklariert. „Der Papst genießt ein so großes Vertrauen unter den Polen, nicht nur als Stellvertreter Christi und höchster Repräsentant der Kirche, sondern zweifellos spielt hier die Tatsache eine ungeheure Rolle, dass das 'unser Papst' ist, jemand der unsere Nation repräsentiert, der mit uns verwandt ist, dessen man sich rühmen und auf den man stolz sein kann, weil er eine unbestrittene internationale Autorität darstellt ${ }^{\text {“26. }}$. Das deklarierte Vertrauen in den Papst Johannes Paul II. übertrifft das deklarierte Vertrauen in die Kirche bei weitem: völliges Vertrauen - 46,7\%, eingeschränktes Vertrauen - 43,4\%, kein Vertrauen $-5,4 \%$, schwer zu sagen oder keine Antwort $-4,5 \%{ }^{27}$.

Ein besonderer Ausdruck der Einstellung der Polen zur Person Johannes Pauls II. war das Miterleben seines Todes und der Jahrestage seines Todes. Besonders der Tod des Papstes stellte für die zeitgenössischen Polen eine intensive und massenhaft erlebte Erfahrung dar, welche von den Soziologen und Psychologen bereits ausführlich geschildert wurde ${ }^{28}$. Manche Psychologen beschreiben die Reaktionen auf die Nachricht vom Todes Johannes Pauls II. in Kategorien einer Agoraversammlung, als ein nie zuvor erlebtes psychosoziales Phänomen. Dazu gehörten solche Dimensionen wie die Tiefe des authentischen

${ }^{25}$ Vgl. Ibidem, S. 145-146.

${ }^{26}$ W. Świątkiewicz, Portret księdza, in: W. Zdaniewicz, S.H. Zaręba (Hrsg.), Kościół katolicki na poczatku trzeciego tysiqclecia w opinii Polaków, Warszawa 2004, S. 108-109.

${ }^{27}$ Vgl. W. Świątkiewicz, Kościelna tożsamość, in: W. Zdaniewicz, S.H. Zaręba (Hrsg.), Kościót katolicki na poczatku trzeciego tysiqclecia w opinii Polaków, Warszawa 2004, S. 129.

${ }^{28}$ Vgl. T. Żukowski, Przeżywanie śmierci Jana Pawła II i jej rocznic, in: T. Żukowski (Hrsg.), Wartości Polaków a dziedzictwo Jana Pawła II, Warszawa 2009, S. 150-182; L. Dyczewski, A. Lewek, J. Olędzki (Hrsg.), Odchodzenie Jana Pawła II do Domu Ojca w polskich mediach, Katowice 2008; J. Soiński, Doświadczenia religijne a postawy studentów w obliczu śmierci Jana Pawła II, Poznań 2008; J. Dziedzic, Żałoba po śmierci Jana Pawła II. Analiza ilościowo-jakościowa Księgi Kondolencyjnej ,Internauci w hołdzie Papieżowi Janowi Pawłowi II”, Kraków 2009. 
Erlebens der Menschen, welche einen Menschen verabschiedeten, der für sie das Vorbild einer Person darstellte; die Skala der Verbreitung und der Parallelität solcher Phänomene mit Massencharakter; das enorme Engagement der Medien in ihrer Berichterstattung über die Reaktionen der Menschen auf die Nachricht vom Tode Johannes Pauls II. sowie dann auch während der Beisetzung des Papstes. Einige Wochen lang kamen die Menschen, die sich versammelten, ,geleitet von dem tiefen Bedürfnis nach dem gemeinsamen Erleben der tiefsten Geheimnisse des menschlichen Lebens auf Erden und ihrer Menschlichkeit, einander näher dank des Zeugnisses des Lebens und des Todes eines Menschen, der zur Verkörperung ihrer Bestrebungen, Vorbilder und Lebensziele geworden war “29.

In den Tagen des Sterbens und des Todes Johannes Pauls II. verband die Polen ein Gefühl der Gemeinschaft; sie erlebten, dass sie etwas sehr Wichtiges verband, und dies in beinahe globalen Dimensionen. „Den tiefsten Ausdruck der erlebten globalen päpstlichen Agora bildete die gemeinsame Erfahrung der Menschen, einem Menschen begegnet zu sein, der ihnen zeigte, wie man würdig, wahrhaft, authentisch und heiligmäßig leben, leiden und sterben kann. Sein Beispiel lehrte, dass man nahe der Menschen leben, leiden und sterben und sie dabei lieben und für sie beten kann - was ihnen ermöglicht, würdevoller zu leben. Durch ein solches Zeugnis brachte er die Menschen einander und dadurch auch Gott näher - unabhängig davon, ob sie nun Christen, Anhänger anderer Konfessionen oder auch anderer weltanschaulicher Überzeugungen waren“30.

Die Autorität Johannes Pauls II. in der polnischen Gesellschaft war zu seinen Lebzeiten enorm. Die geistige Verbundenheit der Polen mit ihm ist weiterhin stark, selbst wenn im Vergleich zu 2005 gewisse Symptome einer Abschwächung erkennbar sind, besonders unter der jungen Generation. Die Mehrheit der Polen deklariert die Kenntnis der päpstlichen Unterweisung und ihre Bereitschaft, sich für die Ausbreitung des Kultes des Heiligen Vaters und die Verbreitung seines Werks einzusetzen. Für viele wurde er zum Vermittler im Gebet zu Gott, und viele haben die Wirksamkeit seiner Fürsprache erfahren. In ihrer Mehrheit sind die heutigen Polen überzeugt, dass das Pontifikat Johannes Pauls II. einen tiefen Einfluss auf ihre eigenen Haltungen und Verhaltensweisen und die ihrer Nächsten ausgeübt hat sowie dass unter seinem Einfluss wichtige Veränderungen in der Welt eingetreten sind. Verhältnismäßig gut fällt die Einschätzung der polnischen Gesellschaft hinsichtlich der Verwirklichung der Unterweisung Johannes Pauls II. aus, mit Ausnahme des Bereichs der öffentlichen Tugenden.

${ }^{29} \mathrm{~A}$. Biela, Nowe zgromadzenie agoralne jako zbiorowe reakcje ludzi na świecie na wiadomość o śmierci Papieża Jana Pawła II, „Roczniki Psychologiczne” 9 (2006) Nr 1, S. 89.

${ }^{30}$ Vgl. Ibidem, S. 91. 
„Diejenigen Elemente der päpstlichen Unterweisung, die den Schutz der christlichen Botschaft vor dem Einfluss der zeitgenössischen Kultur zum Ziel hatten, wurden von seinen Landsleuten nicht generell gebilligt. Deutlich erkennbar ist vor allem eine Distanzierung von seiner Lehre zum Thema der Sexualmoral und auch in einigen Fragen des Lebensschutzes. [...] Einerseits wird der Papst als eine Wärme ausstrahlende Person wahrgenommen, die den Gegenstand allgemeinen Wohlwollens und bedingungsloser Akzeptanz darstellt. Andererseits sehen die Respondenten in ihm einen Lehrer, dessen Botschaft schwierig und vielleicht etwas zu anspruchsvoll ist. Aber durch dieses Verhältnis zu den Worten des Heiligen Vaters wird die Einstellung zur Person Johannes Pauls II.

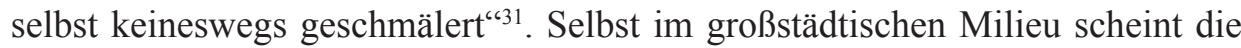
Autorität des Papstes unanfechtbar zu sein. Von den erwachsenen Warschauern, die im Jahre 2007 im Rahmen des sogenannten „Warschauer Barometers“ befragt wurden, deklarierten $21 \%$ ganz entschieden, sich in ihrem Leben von den Weisungen Johannes Pauls II. leiten zu lasen, 49\% - eher ja (zusammen also $70 \%$ ), $11 \%$ - eher nein, 4\% - entschieden nein und 16\% - schwer zu sagen. Im Jahre 2009 waren noch mehr Warschauer der Ansicht, dass Johannes Paul II. für sie eine wichtige moralische Autorität darstellt: entschieden ja $-66 \%$, eher ja $25 \%$, eher nein $-3 \%$, entschieden nein - 2\% und schwer zu sagen - 5\% (Angaben von Paweł Gierech vom Warschauer Zentrum für das Denken Johannes Pauls II.).

\section{Die Autorität Johannes Pauls II. in der Meinung Jugendlicher}

In der pluralistischen Gesellschaft stehen die Jugendlichen vor einem riesigen Angebot von Lebenskonzeptionen und religiösen Überzeugungen. Unter den Bedingungen der Säkularisierung besitzt die Religion kein Monopol mehr für die Persönlichkeits- und die soziale Integration (Einschränkung der exklusiven Funktionen). Die sozio-kulturellen Werte und Normen werden nicht mehr ausschließlich durch die Religion legitimiert. Für viele junge Menschen ist es völlig normal, zwischen vielen verschiedenen Interpretationen des Lebens, des Sinnes und des religiösen Glaubens zu wählen („Bastelreligion“, Logobildung). Solche Werte wie Selbstdefinierung (Selbstbestimmung), Emanzipation, Kreativität, Mobilität, Flexibilität, Ungebundenheit, Freiheit u.dgl. gewinnen immer mehr an Bedeutung. Viele junge Menschen wollen sich ihr Leben auf ihre Art und nach ihren eigenen Vorlieben zurechtlegen. Ihre Beziehungen zu den Institutionen

${ }^{31}$ K. Koseła, Opinie o pontyfikacie Jana Pawła II, in: T. Żukowski (Hrsg.), Wartości Polaków a dziedzictwo Jana Pawta II, Warszawa 2009, S. 147-148. 
erhalten einen individuellen Charakter, die Subjektivität überwiegt gegenüber dem Gehorsam, der Gruppendisziplin und den gemeinsamen Verpflichtungen. Auch die Religiosität und die Verbundenheit mit der Kirche unterliegen den Gesetzmäßigkeiten der Autonomie und Selbstbestimmung (religiöse und kirchliche Souveränität).

Es steht außer Zweifel, dass die religiösen Erfahrungen Jugendlicher, die sie von ihren Begegnungen mit Johannes Paul II. von verschiedenartigen von Jugendlichen und für Jugendliche organisierten Zusammenkünften mitgebracht haben, zu einer Vertiefung des religiösen Lebens eines Teils der polnischen Jugend beigetragen haben. Vom soziologischen Gesichtspunkt aus können wir nicht viel über die „Generation JP2“ sagen. Wir wissen nicht, ob eine solche Generation überhaupt existiert und was sie auszeichnet. Ganz gewiss gibt es in Polen viele junge Menschen, die von der Person Johannes Pauls II. fasziniert sind und die dadurch von einem rein deklarativen oder traditionellen zu einem stark fundierten, erfahrenen und persönlichen Glauben kommen. Die religiösen Überzeugungen werden für sie - durchaus im positiven Sinne - immer öfter zu einer Angelegenheit ihrer persönlichen Wahl. Die Veränderungen in der Religiosität der polnischen Jugend wirken sich ganz gewiss auch auf ihre Einstellung zum Papst Johannes Paul II. aus.

Józef Baniak hat in seinen 1983-1991 in Kalisz durchgeführten soziologischen Untersuchungen unter Gymnasiasten und Studenten die These legitimiert, dass „Johannes Paul II. nicht nur ein vorzüglicher, talentierter religiöser und geistiger Führer der katholischen Kirche [ist], sondern auch ein authentisches personales Vorbild, das Modell eines voll und ganz seiner seelsorglichen Mission hingegebenen Priesters, ein mit spezifischen Charakterzügen ausgestattetes Vorbild: mit charismatischen, religiösen, geistigen, moralischen und natürlichen Eigenschaften, mittels derer er riesige Menschenmassen auf der ganzen Welt für sich einnimmt und auch viele junge Männer für das Priestertum gewinnt, so dass die Zahl der Priester- und Ordensberufungen wieder zunimmt“ ${ }^{\star 32}$. Im Jahre 1991 waren $82,9 \%$ der befragten Gymnasiasten und $68,8 \%$ der befragten Studenten voll und ganz der Ansicht, dass Johannes Paul II. ein personales Vorbild und Modell eines Priesters ist, während $12,2 \%$ bzw. 16,0\% dies verneinten und 4,9\% bzw. 15,2\% zu diesem Thema keine eigene Meinung hatten oder die Frage nicht beantworteten. In den Jahren 1983-1991 erhöhten sich die Kennziffern der

32 J. Baniak, Papież Jan Pawet II jako wzór osobowy i model kapłana-duszpasterza $w$ świetle opinii i oceny młodzieży polskiej, „Ateneum Kapłańskie” 83 (1991) nr 2-3 (495-496), S. 298. 
Zustimmung zu Johannes Paul II. als Muster eines ehrlichen Menschen und als Vorbild für Priester und Bischöfe um mehrere Prozentpunkte ${ }^{33}$.

Die Respondenten aus Kalisz verwiesen in ihrer Charakteristik der Persönlichkeit Johannes Pauls II. auf die Bedeutung seiner religiösen und seiner natürlichen Eigenschaften, wobei sie seine religiösen Eigenschaften und Aktivitäten stärker betonten. „Unter diesen Eigenschaften und Aktivitäten nannten sie an erster Stelle die 'göttliche Berufung zum Priesteramt', mit der, wie sie sagten, 'Gott diesen Papst auf besondere Weise beschenkt hat'. Große Wertschätzung genießen auch sein Glaube und sein Gottvertrauen, seine ehrliche Frömmigkeit sowie seine Liebe zum Gebet und zur religiösen Besinnung. Oft sagten sie, der Papst würde sich während seines individuellen Gebets am liebsten auf Knien, in Stille und Konzentration mit Gott 'unterhalten' und Ihm dabei die verschiedenen Angelegenheiten und Sorgen vorlegen - sowohl seine eigenen als auch die der Kirche und aller Menschen. In der heutigen Zeit ist Johannes Paul II. das authentische Vorbild eines an Gott glaubenden und zu Ihm betenden Menschen, der um die Grenzen menschlicher Möglichkeiten weiß und gern der Liebe und Allmacht Gottes vertraut, der im Gebet seine verborgensten Probleme und Sorgen sowie die der anderen Menschen vor Gott bringt ${ }^{\star * 34}$.

Die religiösen Eigenschaften und Aktivitäten des Papstes akzeptierten insgesamt 77,3\% der Respondenten (78,4\% der Gymnasiasten und 74,9\% der Studenten), seine moralischen Eigenschaften und Aktivitäten - 70,7\% (71,6\% der Gymnasiasten und 69,8\% der Studenten), seine natürlichen Aktivitäten 68,3\% (70,3\% der Gymnasiasten und 66,4\% der Studenten). Die Befürwortung dieser Eigenschaften nahm in den Jahren 1983-1991 etwas zu. „Diese Zunahme umfasst das Interesse der Jugendlichen an allen Eigenschaften und Formen der Aktivität des Papstes, wobei der religiöse und der moralische Bereich in beiden Gruppen deutlich exponiert wird, obwohl die Gymnasiasten stärker von der idealen Persönlichkeit des Papstes fasziniert sind. Die Einstellungen der befragten Jugendlichen zum Papst besitzen neben ihrem soziologischen auch einen wichtigen pädagogisch-psychologischen Aspekt, der auf das nachdrückliche Bestreben der jungen Menschen verweist, ihre Gefühle und Wünsche auf ein ihr Vertrauen verdienendes Vorbild eines 'guten Menschen' sozusagen zu 'projizieren', auf das sie sich stützen können, ohne zu befürchten, ihre eigenen Lebensziele und Bestrebungen aufgeben zu müssen; ein Vorbild, auf das junge Menschen, die ihren Platz im 'erwachsenen' Leben suchen, wozu sie

\footnotetext{
${ }^{33}$ Vgl. Ibidem, S. 299.

${ }^{34}$ Vgl. Ibidem, S. 302.
} 
treffende Weisungen, Empfehlungen und Systemlösungen benötigen, alle vom existenziellen Gesichtspunkt wichtigen Probleme projizieren können“35.

In den 2003-2004 durchgeführten nicht repräsentativen Untersuchungen deklarierten sehr unterschiedliche soziale Gruppen (Gymnasiasten und Oberschüler, Priesteramtskandidaten aus dem Priesterseminar, Obdachlose, Strafgefangene, Bewohner von Alten- und Pflegeheimen) sehr positive Meinungen und Urteile über den Papst. Von den Befragten insgesamt erklärten 92,84\%, sie seien stolz, dass Johannes Paul II. ein Pole ist, und nur etwas über $1 \%$ waren nicht stolz darauf oder diesbezüglich gleichgültig; $70,30 \%$ aller Befragten zufolge mobilisierte sie der Papst ganz entschieden zur Überwindung von Schwierigkeiten im Leben, 4,86\% - nur manchmal, 10,44\% gar nicht, 13,76\% - ohne Antwort oder unfähig, den Einfluss des Papstes auf ihr Leben zu definieren; fast $80 \%$ der Befragten bemerkten einen Einfluss Johannes Pauls II. auf ihre nationale Identität, 6,35\% - keinen solchen Einfluss; über 70\% deklarierten seinen Einfluss auf ihren Patriotismus, 7,85\% - keinen solchen Einfluss (verhältnismäßig häufig war diesbezüglich „keine Antwort“). Besonders positiv beurteilten die befragten Personen den Einfluss des Papstes auf ihr religiöses Leben ${ }^{36}$.

Die Gymnasiasten aus Sandomierz und Chobrzany äußerten sich in den Jahren 2002-2004 über Johannes Paul II. als nachahmenswertes Vorbild. Die Antworten gestalteten sich folgendermaßen: ja, in seiner gesamten Tätigkeit $54,9 \%$; ja, aber nur in einigen Bereichen - 29,0\%; eher nicht und entschieden nicht - 8,8\%; schwer zu sagen - 7,3\%. Im Jahre 2004 teilten 83,0\% der Befragten die Ansicht, der Papst habe sie zur Veränderung ihres Lebens ermutigt, 83,0\% dass er dem Menschen neue Wege weist, 64,8\% - dass er die Menschen aus ihrer Lethargie weckt, 66,7\% - dass er ein Mediator in Glaubensdingen ist, und 30,2\% - dass er auch politische Autorität besitzt. Die befragten Jugendlichen schrieben dem Papst einen Einfluss auf verschiedene Lebensbereiche zu: den Sturz des Kommunismus - 47,1\% der Befragten, die Ausweitung des Friedens in der Welt - 93,7\%, die Verbindung der Christenheit - 90,5\%, die moralische Erneuerung unter den Gläubigen - 91,8\%, die Vertiefung der Religiosität - 90,6\%, die Sorge um Gerechtigkeit und Freiheit des Menschen - 83,6\%, die Sorge um Arme und Kranke $-84,9 \%$, die Sorge um die Position Polens auf der internationalen Arena

${ }^{35}$ Ibidem, S. 304; J. Baniak, Ksiadz w oczach młodzieży. Obraz kaptana w świadomości młodzieży licealnej i akademickiej (na przykładzie Kalisza), Poznań 1993.

${ }^{36}$ Vgl. J. Śledzianowski, Wpływ Jana Pawła II na życie rodaków, Kielce 2005, S. 113-204; J. Śledzianowski, Jan Pawet II - nadzieja narodu polskiego, Kielce 2002; J. Śledzianowski, Wptyw Jana Pawta II na życie młodzieży akademickiej, „Kielecki Przegląd Diecezjalny” 81 (2005) Nr 2, S. 212-222. 
- 53,5\%, die Überwindung des Bösen - 81,8\%, die Sorge um die Aktivität der Kirche in Polen $-80,5 \%{ }^{37}$.

In dem vom Verlag für Schule und Pädagogik im Schuljahr 2001/2002 unter der Losung „Goldene Liste der Autoritäten“ organisierten Wettbewerb sollten die Gymnasiasten in freier Form Silhouetten von sechs bis zehn der von den Schülern ihrer Schule besonders geschätzten oder bewunderten Personen präsentieren. In 408 von insgesamt 497 Schulen stand Johannes Paul II. an der Spitze dieser „Goldenen Liste“, an zweiter Stelle wurde Mutter Teresa von Kalkutta genannt (in 231 Schulen), und den dritten Platz nahmen die engsten Familienmitglieder der Schüler ein (in 206 Schulen). Als Begründung für die Wahl der Person Johannes Pauls II. wurden seine Fähigkeit zur Vergebung, seine Begabung fürs Zuhören und den Dialog sowie sein überdurchschnittliches Wissen und seine Bescheidenheit genannt. Mutter Teresa wurde als Beispiel einer großen Liebe und Hingabe für die Kranken und Leidenden gesehen ${ }^{38}$.

In den 2002 in Bydgoszcz, Toruń, Włocławek und einigen Kleinstädten dieser Region durchgeführten soziologischen Untersuchungen verwiesen $11,6 \%$ der befragten Mittelschüler und Studenten auf ihre Eltern als höchste Autorität, 10,7\% - auf Johannes Paul II., 9,8\% - auf ihre Mutter und von 0,5\% bis $4,4 \%$ auf andere Personen. In der gesamten Probe deklarierten $21,1 \%$ der Befragten das Fehlen einer solchen Autorität, während 26,2\% diese Frage nicht beantworteten. Die Respondenten verwiesen sowohl auf positive als auch auf negative Eigenschaften der Geistlichen: 43,3\% der Befragten äußerten mehr oder weniger positive oder neutrale Ansichten über den Klerus, während mehr als die Hälfte von ihnen den Priestern gegenüber kritisch eingestellt war. Aber auch diese Meinungen scheinen sich nicht negativ auf ihr Urteil über die Unterweisung und die Aktivitäten Johannes Pauls II. ausgewirkt zu haben ${ }^{39}$.

In ihren allgemeinen Formen war und ist die Autorität Johannes Pauls II. in der polnischen Gesellschaft unbestritten, wobei sie in Kreisen der Jugend etwas weniger ausgeprägt ist. Selbst die in den neunziger Jahren in Erscheinung tretenden antiklerikalen Tendenzen betrafen nie seine Person selbst. In Detailfragen dagegen muss differenziert werden. Hinsichtlich der moralischen Jurisdiktion werden seine Kompetenzen zwar nicht direkt in Frage gestellt, aber in der Praxis bleiben sie dann doch oft unberücksichtigt. In gewissem Sinne stellt

37 Vgl. M. Rewera, Autorytety w świadomości młodzieży licealnej, Stalowa Wola 2008, S. $242-250$.

${ }^{38}$ Vgl. A. Przecławska, Młodzież $i$ autorytety - refleksje na marginesie wyników badań, in: B. Gołębiowski (Hrsg.), Autorytety polskie, Łomża 2002, S. 244.

39 Vgl. T. Biernat, Społeczno-kulturowe uwarunkowania światopogladu młodzieży $w$ okresie transformacji, Toruń 2006, S. 221, 239-243. 


\section{2

der britische Soziologe David Martin fest, dass „der Papst für die katholische Identität eher ein charismatisches Totem darstellt anstatt einer Autorität in Fragen des Lebensstils oder als jemand, der entscheiden darf, wie die Familie oder das Sexualleben organisiert werden soll ${ }^{\leftarrow 40}$. Es scheint, dass im polnischen Katholizismus - und besonders unter der Jugend - die Zahl derer zunimmt, die ohne Bezugnahme auf die katholische Lehre über moralische Fragen entscheiden und sich dementsprechend verhalten, zumindest in einigen Bereichen der Moral. In Bezug auf die Sexualmoral wird die Autorität des Papstes nur in beschränktem Umfang anerkannt, und manchmal ist sogar die Rede davon, dass er auf diesem Gebiet eine gewisse Niederlage erlitten habe.

Selbst wenn die autoritäre Orientierung in Kreisen der Jugend deutlich zurückgeht, so bedeutet dies keineswegs im gleichen Maße eine Abschwächung der Autoritäten überhaupt. Glaubwürdige Autoritäten werden akzeptiert, nicht legitimierte Autoritäten dagegen abgelehnt. Johannes Paul II. bleibt für die meisten Polen auch weiterhin die größte religiöse und moralische Autorität, weniger nach dem Prinzip einer „Führer-Autorität“ als eher einer „BeispielAutorität ${ }^{\star 41}$. Er zeigte nicht nur den Weg, den der Christ beschreiten soll, sondern - und vielleicht gerade vor allem - wie er auf diesem Weg in Richtung des Guten fortschreiten kann. Die Jugend war für ihn keine „im Stich gelassene“, sondern eine befreundete Generation. Die Veränderungen in den anerkannten Autoritäten zeugen nicht von einer Krise der Autoritäten, sondern von deren Wandlungen. In demokratischen und pluralistischen Gesellschaften muss man sich seine Autorität erst verdienen, und dies betrifft - mutatis mutandis - auch die Kirche. In Kreisen der Jugend fungierte - und fungiert - Johannes Paul II. mehr als religiöse und weniger als moralische Autorität (zum Beispiel werden seine Weisungen auf dem Gebiet des Lebensschutzes nicht vollständig akzeptiert).

Wir sind nicht imstande, ein alternatives Experiment durchzuführen und danach zu fragen, wie der polnische Katholizismus aussehen würde, wenn es keinen polnischen Papst gegeben hätte. Ganz allgemein könnte man sagen, dass Polen ohne die Unterweisung und den Einfluss Johannes Pauls II. heute von einer noch viel größeren moralischen Krise betroffen wäre, besonders in Fragen des Ehe- und Familienlebens. Selbst in so kontroversen Angelegenheiten wie der Abtreibung haben vom Gesichtspunkt der Lehre der Kirche wichtige Veränderungen stattgefunden. Auch wenn die Mehrheit oder zumindest ein

${ }^{40}$ D. Martin, Religia, świeckość, sekularyzm i integracja europejska, „Res Publica Nowa” 19 (2006) Nr 1, S. 28.

41 Odczarować oczarowane. Rozmowa $\mathrm{z}$ profesorem Zygmuntem Baumanem, „Życie Duchowe" (2000) Nr 24, S. 19. 
beträchtlicher Teil der Katholiken den Standpunkt der Kirche in dieser Frage nicht mehr in vollem Umfang teilt, stellt der Schwangerschaftsabbruch dennoch nur für eine kleine Minderheit der Polen überhaupt kein moralisches Problem dar. Die Abtreibung wird jedenfalls nicht als ein üblicher medizinischer Eingriff ohne größere moralische Bedeutung angesehen (sogenannte Abtreibung auf Wunsch).

Selbst wenn es zutrifft, dass die moralische Unterweisung Johannes Pauls II. im Bewusstsein der Katholiken nur auf teilweisen Widerhall stößt, wird er dennoch zu Recht als „Papst der Familie“ bezeichnet, auch wenn es schwerfällt, seinen Einfluss auf diesem Gebiet zu präzisieren. Man kann der Feststellung zustimmen, dass „das Pontifikat Johannes Pauls II. dazu beigetragen [hat], den schlimmsten selbstzerstörerischen Tendenzen in der Familie entgegenzusteuern, die im Zusammenhang mit den 'Propheten' der sexuellen Revolution in den siebziger Jahren in Erscheinung getreten sind“42. Trotz des allgemein deklarierten Vertrauens in Johannes Paul II. sind die Polen weit davon entfernt, seine Morallehre in toto zu akzeptieren. Recht häufig schreiben sie dem eigenen Gewissen den Rang einer letztendlichen Autorität in Moralfragen zu. Sie sind der Ansicht, dass die Entscheidung darüber, was gut und was böse ist, in der Kompetenz des Einzelnen liegt, in seinen individuellen Überzeugungen, und nicht aus irgendwelchen Regeln resultieren muss, die dem Menschen von außen aufgezwungen werden. Dies kann von einer weitreichenden Krise institutioneller Autoritäten überhaupt sowie von einer außerordentlichen Promotion des eigenen „Ich“ zeugen. Johannes Paul II. fungiert in der polnischen Gesellschaft eher als eine symbolische Autorität und weniger als eine die Einstellungen und das alltägliche Verhalten seiner Landsleute beeinflussende Autorität.

\section{Schlussbemerkungen}

Die Rolle Johannes Pauls II. in den politischen, kulturellen und ethischen Veränderungen und seine moralische und geistige Autorität wird von vielen Soziologen und Philosophen unterstrichen. Piotr Sztompka schreibt, der Papst habe die Polen aus ihrer Lethargie geweckt und ganz verschiedene Kräfte in der polnischen Gesellschaft vereint - „während seiner ersten Pilgerreise in sein Vaterland, noch im Jahre 1979, als wir plötzlich in Begeisterung und Hoffnung vereint waren, im Gefühl wiedergewonnener Würde und Einheit, während der

${ }^{42}$ Wyzwania stojace przed rodzina na poczatku trzeciego tysiaclecia (Dokument końcowy IV spotkania przewodniczących europejskich komisji episkopatów do spraw rodziny i życia), „L'Osservatore Romano” 24 (2003) Nr 11-12, S. 45. 
Messen mit dem Papst, und zehn Jahre später konnten wir uns dann gemeinsam an den Runden Tisch setzen - dieses herrlichste Möbelstück unserer Geschichte - um 'das Antlitz der Erde, dieser Erde [zu] verändern', wie der Papst gerufen hatte. Ich habe an einer solchen Papstmesse in Krakau-Błonie teilgenommen. Das war nicht nur ein religiöses und patriotisches Erlebnis, sondern auch eine meiner wichtigsten professionellen Erfahrungen. Denn zwischen diesen zwei Millionen Menschen, die noch jeder für sich allein hierher gekommen waren, jeder von woanders, die unter der Last ihrer Sorgen und täglichen Schwierigkeiten niedergedrückt waren, entstand plötzlich eine Gemeinschaft, eine communitas. Danach gingen wir dann schon ganz anders nach Hause, mit hoch erhobenen Häuptern“43.

Und Leszek Kołakowski schrieb in seinem vom Verlag ZNAK veröffentlichten umfangreichen Interview über seine Kontakte mit Johannes Paul II., wobei er die Größe dieses Papstes und seine Sympathie für ihn unterstrich und auch seinem Gefühl Ausdruck verlieh, dass dieser Mann mit Heiligkeit bedacht war: „Ich denke, dass das Pontifikat Johannes Pauls II. ganz beträchtlich dazu beigetragen hat, den traditionellen Gegensatz von Progressismus und Integrismus aufzuheben. Natürlich sind mir die Kritiker des Papstes bekannt, die ihm Traditionalismus vorgeworfen haben und die wahrscheinlich erst dann zufrieden gewesen wären, wenn Johannes Paul II. erklärt hätte, dass wenn es keinen Gott gäbe, sowohl die Abtreibung als auch homosexuelle Ehen erlaubt sein müssten und die Kirche eine Befreiung im Geiste linksgerichteter politischer Parteien anstreben würde. Aber lassen wir diesen Unsinn beiseite. Ich meine, dass der polnische Papst wesentliche Schritte unternommen hat, damit der Gedanke der Menschenrechte nicht nur als eine mit der christlichen Tradition übereinstimmende, sondern auch als eine genuin christliche Idee - in der Kirche heimisch wird. Und was seinen Konservatismus betrifft, so hätte der Begriff der Kirche und des Christentums keinen Sinn mehr, wenn man davon ausginge, alles dort könne und müsse der Veränderung unterliegen. Die Kirche muss von Natur aus konservativ sein - in dem Sinne, dass sie an etwas glaubt, was trotz aller Veränderungen, denen sie unterliegt - Veränderungen der Liturgie, der Ausdrucksformen, der Lehrsprache einen gewissen unveränderlichen Kern bewahrt. Als Johannes Paul II. die Worte Christi wiederholte: 'Fürchtet euch nicht!', vertrauten Millionen von Menschen

${ }^{43}$ P. Sztompka, Cud 1989 roku w perspektywie socjologicznej, „Alma Mater. Miesięcznik Uniwersytetu Jagiellońskiego" (2009) Nr 115-116, S. 17. 
darauf, dass dies ein Mensch sagt, der sich eben nicht fürchtet, der in völligem und unbedingten Vertrauen auf Gott lebt“444.

Bei der Analyse der Wandlungsprozesse in Ostmitteleuropa und besonders in Polen wäre es schwer, die Rolle zu übergehen, die Johannes Paul II. dabei gespielt hat. Bereits während seiner ersten Pilgerreise in sein Heimatland im Jahre 1979 brachte es der Papst fertig, der polnischen Nation ihren Elan wiederzugeben und die Verwurzelung Polens im katholischen Glauben und in der europäischen Zivilisation zu festigen. Manche Forscher halten diese Pilgerreise für den Beginn der polnischen Solidarność-Revolution, die zum Untergang des Sowjetregimes in Ostmitteleuropa und zur Überwindung der in Jalta beschlossenen Teilung Europas führte. Sie durchbrach die aus der langen kommunistischen Vorherrschaft resultierende Mutlosigkeit der Nation und stärkte den Wunsch nach Befreiung, die nun auch wieder für möglich gehalten wurde. Kardinal Stanisław Dziwisz zufolge war der erste Besuch des Papstes in Polen - vom historischen Gesichtspunkt aus gesehen - der wichtigste. Die Menschen hörten auf, sich zu fürchten, eine innere Freiheit tat sich ihnen auf. Das Pontifikat Johannes Pauls II. hat sowohl die Kirche als auch die Welt verändert ${ }^{45}$.

Johannes Paul II. nahm und nimmt eine besondere Position in der polnischen Gesellschaft ein, besonders im religiösen Bewusstsein der Polen. Das Charisma des polnischen Papstes und die enorme Autorität, der er sich in der Gesellschaft erfreute, weckte und weckt Tendenzen zur Evangelisierung ${ }^{46}$. Als Papst besuchte er Polen mehrmals; insgesamt weilte er über zwei Monate lang in unserem Land. Sein Einfluss auf das Ansehen der Religiosität und die Position der katholischen Kirche ist unbestritten. Manchmal wird die Überzeugung geäußert, der Papst habe eine Art Schutzschirm über den polnischen Katholizismus und die polnische Bischofskonferenzausgebreitet, pastorale Visionen geliefert und konkrete Hinweise zum Handeln gegeben. Manche bezeichneten ihn als Garanten für die Vitalität des polnischen Katholizismus. Gleichzeitig stimmte die entschiedene Mehrheit der Polen der Feststellung zu, dass der Papst zwar von seinen Landsleuten geliebt

\footnotetext{
${ }^{44}$ Czas ciekawy, czas niespokojny. Część II. Z Leszkiem Kołakowskim rozmawia Zbigniew Mentzel, Kraków 2008, S. 120-121.

${ }^{45}$ Vgl. Demontaż ,żelaznej kurtyny” rozpoczą się w Gnieźnie a nie w Berlinie. Rozmowa z metropolitą krakowskim kard. Stanisławem Dziwiszem, byłym sekretarzem Jana Pawła II, „L'Osservatore Romano” 30 (2009) Nr 10, S. 47-48.

${ }^{46} \mathrm{Vgl}$. A. Jasińska-Kania, Orientacje aksjologiczne Polaków na tle europejskim, in: A. Kojder (Hrsg.), Jedna Polska? Dawne i nowe zróżnicowania społeczne, Warszawa 2007, S. 115.
} 
wird, diese aber seinen Weisungen und Empfehlungen im allgemeinen nicht Folge leisten (nur $11 \%$ widersprachen dieser These) ${ }^{47}$.

Man kann hypothetisch davon ausgehen, dass das Charisma Johannes Pauls II. - zumindest im symbolischen Bereich - den in der polnischen Gesellschaft zunehmenden Tendenzen zum moralischen Relativismus und Permissivismus sowie zum Pragmatismus im Alltagsleben entgegengesteuert hat. Johannes Paul II. bleibt in der polnischen Gesellschaft nicht nur eine Autorität und ein moralisches Vorbild, sondern er hat mit seinem ganzen Leben bewiesen, dass es sich lohnt, ,jemand“ zu sein. Als Autorität aus dem Bereich des Sacrum war er gleichzeitig sehr menschlich. Selbst bei denjenigen, die der Ansicht sind, dass es in der polnischen Gesellschaft überhaupt keine Autoritäten mehr gibt, sind manche noch geneigt, den polnischen Papst als moralische Autorität gelten zu lassen.

Es scheint, dass der Papst im Bewusstsein der Polen eher als sichtbares Oberhaupt der katholischen Kirche fungiert anstatt als Statthalter Christi auf Erden. Zumindest ergibt sich dies aus der CBOS-Befragung vom Juni 2006, der zufolge 34\% der befragten Polen die Antwort wählten: „Er ist der Repräsentant Jesu Christi auf Erden“, 60\% dagegen: „Er ist nur das Oberhaupt der katholischen Kirche“. Die erste (theologisch korrektere) Aussage wählten 37\% der Respondenten mit Grundschulbildung und 31\% mit Hochschulbildung, 37\% der befragten Dorfbewohner und 28\% der Respondenten in Städten mit mehr als 500.000 Einwohnern, 43\% der regelmäßig praktizierenden Gläubigen, 27\% der unregelmäßig praktizierenden Gläubigen, $19 \%$ dernicht praktizierenden Gläubigen und 19\% der Ungläubigen. Nicht einmal bei den regelmäßig praktizierenden Gläubigen wird die Ansicht, dass der Papst der irdische Stellvertreter Christi ist, von der Mehrheit der Befragten geteilt ${ }^{48}$.

Zweifellos wirkte sich die Person Johannes Pauls II. positiv auf das Ansehen der Religiosität und der Kirche in Polen aus, auch wenn dieser Einfluss empirisch wohl kaum messbar sein dürfte. Die mit der Krankheit und dem Tod des Papstes verbundenen Erlebnisse übten einen bedeutsamen Einfluss auf das Leben vieler Polen aus (das sogenannte „Papstjahr"). Allerdings bleibt zu bezweifeln, ob der polnische Katholizismus, der in der Nachkriegszeit seinen Volks- und Massencharakter aufrechterhalten konnte, unter anderem dank seiner Rückenstärkung durch den Einfluss Johannes Pauls II., nun auch in den nächsten

${ }^{47}$ Vgl. R. Boguszewski, Polak - nie zawsze katolik? Polska religijność w latach 1989-2008 na podstawie badań CBOS, „Więź” 51 (2008) Nr 9, S. 18.

${ }^{48}$ Vgl. Nauki Benedykta XVI. Komunikat z badań TNS OBOP (czerwiec, 2006), Warszawa 2006, S. 7-8. 
Jahrzehnten nach dem Tod dieses Papstes seinen bisherigen Charakter bewahren wird. Aber selbst wenn der Einfluss Johannes Pauls II. auf das religiöse und moralische Bewusstsein der Polen zurückgehen sollte, wird er mit Sicherheit noch für lange Zeit wichtig und bedeutsam bleiben, und die Säkularisierung der polnischen Gesellschaft wird nur langsame Fortschritte machen (schleichende Säkularisierung). Sicher wird er als Quell der Desäkularisierung in Polen fungieren, als Garant dafür, dass unser Land ein „Sonderfall“ in Europa bleibt. Wichtig ist, dass die religiöse, ethische und soziale Unterweisung Johannes Pauls II. nicht den Mechanismen statischer Vererbung unterliegt, sondern auch als Quell eines authentischen und kritischen Diskurses fungiert sowie eine Inspiration zum Handeln im privaten und im öffentlichen Leben darstellt. Die Aufgaben, vor die sich die katholische Kirche in Polen heute gestellt sieht, wo sie sich nicht mehr unmittelbar auf die Autorität und die Unterstützung Johannes Pauls II. berufen kann, sind schwierig, aber ihre Bewältigung ist durchaus möglich.

Das Pontifikat Johannes Pauls II. war sehr wichtig für den polnischen Katholizismus, und der Tod dieses Papstes bildete den Abschluss einer Etappe, die bedeutsame Veränderungen in den Gefühlen und Urteilen vieler Polen bewirkt hat: „Erstens gewisse Veränderungen im Selbstbewusstsein, was im Auftreten des Begriffes 'Generation JP2' resultierte. Zweitens dauert der Prozess der institutionellen Erinnerung und Dokumentierung des Erbes Johannes Pauls II. noch an. Es ist schwerer zu sagen, in welchem Grade die Polen imstande sein werden, dieses Erbe in lebendige Institutionen und Lebensformen umzusetzen, die zu einer geistigen und kulturellen Revitalisierung Polens führen können. Für heute kann man sagen, dass es ein Potential und Ressourcen gibt, die die Zeit der (politischen und ökonomischen) Systemtransformation überdauert haben; allerdings fehlt es an einer 'Formel', die diese Ressourcen mit den Erwartungen verklammern würde. Vielleicht braucht es, wie Benedikt XVI. dies formuliert hat, 'vor allem Charismatiker - die imstande sind, das Leben zu entzünden'. Das allerdings entzieht sich unserem Einfluss“ ${ }^{\text {499. }}$.

Der polnische Katholizismus unterliegt mehr oder weniger radikalen Wandlungen in Richtung einer Abschwächung bestimmter Sektoren bei gleichzeitiger Stärkung anderer, und dies wird auch weiterhin der Fall sein. Es wäre riskant, Prognosen über die quantitativen Ausmaße dieses Phänomens anzustellen. Mit Sicherheit wird die Kirche der Zukunft eine vielstimmige (,polyphone“), pluralistische, vielseitige, für andere offene Kirche mit anderen (und nicht gegen andere) sein müssen. Als Institution und Gemeinschaft „von langer Dauer“ verändert sich die Kirche allmählich („Kontinuität in Wandelbarkeit“), und selbst

\footnotetext{
${ }^{49}$ T. Szawiel, Religijna Polska, religijna Europa, „Więź” 51 (2008) Nr 9, S. 35.
} 
die starken Einflüsse einer sozio-ökonomischen Modernisierung müssen sich nicht in derselben Richtung auf Veränderungen im Bereich der Werte auswirken, d.h. in Richtung einer Säkularisierung der Religion und der Moral. Die polnische Gesellschaft kann auch in Zukunft ihr etwas anderes System religiöser und moralischer Werte bewahren und ein einmaliger „Sonderfall“ in Europa bleiben.

Die Kirche ist kein Dienstleistungsbetrieb, der sich voll und ganz den Geschmäckern ihrer Konsumenten anpassen müsste („,wenn sich die Erwartungen ändern, ändern wir uns auch“; „unsere Philosophie beruht auf der Erfüllung aller eurer Wünsche"). Sie ist vor allem eine religiöse Institution, die zwischen den Menschen und Gott vermittelt. Dennoch erfüllt sie ihre Mission in einem konkreten sozialen Umfeld und immer unter ganz bestimmten sozio-kulturellen Bedingungen. Die sich wandelnden Haltungen und anerkannten Werte ihrer Mitglieder müssen wahrgenommen, analysiert, interpretiert und erklärt werden. Die sich wandelnden Formen der Zugehörigkeit zur Kirche stellen schon heute eine wichtige Herausforderung für sie dar und verlangen nach einem authentischen Dialog zwischen Geistlichen und Laien innerhalb der kirchlichen Gemeinschaft. Denn zwischen einer Kirche der „Befehle“ und einer Kirche der „Angebote“ existiert durchaus noch eine reichhaltige Skala mittlerer Lösungen.

\section{Bibliography}

Aktualne problemy i wydarzenia. Komunikat z badań CBOS (do użytku wewnętrznego), Warszawa 2009.

Baniak J., Ksiqdz w oczach młodzieży. Obraz kapłana w świadomości młodzieży licealnej i akademickiej (na przykładzie Kalisza), Poznań 1993.

Baniak J., Papież Jan Pawet II jako wzór osobowy i model kapłana-duszpasterza w świetle opinii i oceny młodzieży polskiej, „Ateneum Kapłańskie” 83 (1991) Nr 2-3 (495496), S. 298.

Biela A., Nowe zgromadzenie agoralne jako zbiorowe reakcje ludzi na świecie na wiadomość o śmierci Papieża Jana Pawła II, „Roczniki Psychologiczne” 9 (2006) Nr 1, S. 89.

Biernat T., Spoteczno-kulturowe uwarunkowania światopogladu młodzieży w okresie transformacji, Torun 2006.

Boguszewski R., Polacy wobec Kościoła oraz nauczania papieża Benedykta XVI dwa lata po śmierci Jana Pawła II. Komunikat z badań CBOS. BS/78/2007, Warszawa 2007.

Boguszewski R., Polak - nie zawsze katolik? Polska religijność w latach 1989-2008 na podstawie badań CBOS, „Więź” 51 (2008) Nr 9, S. 18. 
Boguszewski R., Wartości $i$ normy $w$ życiu Polaków. Komunikat z badań CBOS. BS/133/2005, Warszawa 2005.

Casanova J., Der Ort der Religion im nachchristlichen Europa, in: K. Michalski (Hrsg.), Woran glaubt Europa? Religion und politische Kultur im neuen Europa, Wien 2007, S. 38-40.

Casanova J., Katolicyzm a sekularyzacja, „Znak” (2008) Nr 10, S. 83.

Centrum Myśli Jana Pawła II. Jan Paweł II w opinii Polaków. Raport z badań społecznych, Warszawa 2007.

Czas ciekawy, czas niespokojny. Część II. Z Leszkiem Kołakowskim rozmawia Zbigniew Mentzel, Kraków 2008.

Demontaż „żelaznej kurtyny” rozpocząt się w Gnieźnie a nie w Berlinie. Rozmowa z metropolitą krakowskim kard. Stanisławem Dziwiszem, byłym sekretarzem Jana Pawła II, „L' Osservatore Romano” 30 (2009) Nr 10, S. 47-48.

Dyczewski L., Lewek A., Olędzki J. (Hrsg.), Odchodzenie Jana Pawła II do Domu Ojca w polskich mediach, Katowice 2008.

Dziedzic J., Żałoba po śmierci Jana Pawła II. Analiza ilościowo-jakościowa Księi Kondolencyjnej „Internauci w hołdzie Papieżowi Janowi Pawłowi II”, Kraków 2009.

Jasińska-Kania A., Orientacje aksjologiczne Polaków na tle europejskim, in: A. Kojder (Hrsg.), Jedna Polska? Dawne i nowe zróżnicowania społeczne, Warszawa 2007, S. 115.

Koseła K., Opinie o pontyfikacie Jana Pawła II, in: T. Żukowski (Hrsg.), Wartości Polaków a dziedzictwo Jana Pawła II, Warszawa 2009, S. 123-149.

Marody M., Mandes S., Polak katolik. O zwiqzkach religijności z tożsamościq narodowa, „Dziennik” (dodatek „Europa” Nr 24) (2006) Nr 48, S. 9.

Martin D., Religia, świeckość, sekularyzm i integracja europejska, „Res Publica Nowa” 19 (2006) Nr 1, S. 28.

Nauki Benedykta XVI. Komunikat z badań TNS OBOP (czerwiec, 2006), Warszawa 2006.

Nosowski Z., Modernizacja potrzebuje religii - i nawzajem, in: J. Szomburg (Hrsg.), Modernizacja Polski. Kody kulturowe i mity, Gdańsk 2008, S. 109-116.

Odczarować oczarowane. Rozmowa z profesorem Zygmuntem Baumanem, „Życie Duchowe" (2000) Nr 24, S. 19.

Przecławska A., Młodzież $i$ autorytety - refleksje na marginesie wyników badań, in: B. Gołębiowski (Hrsg.), Autorytety polskie, Łomża 2002, S. 244.

Rewera M., Autorytety w świadomości młodzieży licealnej, Stalowa Wola 2008.

Roguska B., Wciórka B., Religijność i stosunek do Kościoła katolickiego, in: K. Zagórski, M. Strzeszewski (Hrsg.), Polska. Europa. Świat. Opinia publiczna w okresie integracji, Warszawa 2005, S. 324-325.

Soiński S., Doświadczenia religijne a postawy studentów w obliczu śmierci Jana Pawta II, Poznań 2008. 
Szawiel T. (Hrsg.), Pokolenie JP2. Przeszłość i przyszłość zjawiska religijnego, Warszawa 2008 .

Szawiel T., Religijna Polska, religijna Europa, „Więź” 51 (2008) Nr 9, S. 32-35.

Sztompka P., Cud 1989 roku w perspektywie socjologicznej, „Alma Mater. Miesięcznik Uniwersytetu Jagiellońskiego" (2009) Nr 115-116, S. 17.

Śledzianowski J., Jan Pawet II - nadzieja narodu polskiego, Kielce 2002.

Śledzianowski J., Wpływ Jana Pawła II na życie młodzieży akademickiej, „,Kielecki Przegląd Diecezjalny" 81 (2005) Nr 2, S. 212-222.

Śledzianowski J., Wpływ Jana Pawła II na życie rodaków, Kielce 2005.

Świątkiewicz W., Kościelna tożsamość, in: W. Zdaniewicz, S.H. Zaręba (Hrsg.), Kościół katolicki na poczqtku trzeciego tysiqclecia w opinii Polaków, Warszawa 2004, S. 129.

Świątkiewicz W., Portret księdza, in: W. Zdaniewicz, S.H. Zaręba (Hrsg.), Kościót katolicki na poczatku trzeciego tysiqclecia $w$ opinii Polaków, Warszawa 2004, S. 108-109.

Wciórka B., Czy Polacy spetniaja oczekiwania Papieża. Komunikat z badań CBOS. BS/158/2003, Warszawa 2003.

Wciórka B., Pierwsza pielgrzymka Jana Pawła II do ojczyzny - rocznicowe refleksje. Komunikat z badań CBOS. BS/83/2009, Warszawa 2009.

Wnuk-Lipiński E., [głos w dyskusji], in: S. Bednarek, A. J. Omelaniuk, A. Tyszka, A. Zieliński (Hrsg.), Kongres Kultury Polskiej 2000, Wrocław-Warszawa 2002, S. 77-78.

Wyzwania stojace przed rodzina na poczatku trzeciego tysiaclecia (Dokument końcowy IV spotkania przewodniczących europejskich komisji episkopatów do spraw rodziny i życia), „L’ Osservatore Romano” 24 (2003) Nr 11-12, S. 45.

Żukowski T., Przeżywanie śmierci Jana Pawła II i jej rocznic, in: T. Żukowski (Hrsg.), Wartości Polaków a dziedzictwo Jana Pawła II, Warszawa 2009, S. 150-182. 